\title{
POTENCIALIDADES DA PROBLEMATIZAÇÃO FREIREANA NO ENSINO DE “DIDÁTICA EM ENFERMAGEM”
}

Rodrigo Otávio Moretti-Pires ${ }^{1}$, Any Karoline Bezerra de Alencar², Elusa Rafaela Hentges Campos², Hadelândia Milon de Oliveira ${ }^{3}$

\begin{abstract}
RESUMO: A implicação do modelo pedagógico na postura dos futuros profissionais é defendida pela literatura. Este estudo teve por objetivo investigar a percepção dos acadêmicos de Enfermagem sobre a utilização de problematização fundamentada nos pressupostos freireanos em uma disciplina de didática. Consiste em pesquisa qualitativa, com dados tratados na perspectiva hermenêutica dialética, oriundos de análise documental dos relatórios produzidos por trinta e quatro alunos de uma Universidade Federal da Região Norte do Brasil, no primeiro semestre de 2009. Os conhecimentos teóricos, a partir do empírico, permitiram a abertura do diálogo, a aproximação da vida dos usuários e autopercepção dos acadêmicos como atores sociais. Concluimos que a problematização do ensino de didática em Enfermagem apresenta potencialidades para uma educação humanizante.
\end{abstract}

PALAVRAS-CHAVE: Educação Superior; Modelos educacionais; Estudantes de enfermagem.

\section{POTENTIAL OF THE FREIRE’S PROBLEMATIZATION ON “NURSING DIDACTICS” TEACHING}

\begin{abstract}
The implication of the pedagogical model on the future professionals' attitude is supported by the literature. This study aimed to investigate the perception of nursing students on the use of Freire's problematization in a discipline of teaching. It's a qualitative research, with data analysis based on the dialectical hermeneutic perspective, arising from documentary analysis of reports produced by thirty-four students from a Federal University of Northern Brazil in the first half of 2009. Theoretical knowledge from the empirical, allowed the opening of the dialogue, the approach of the users' lives and self-perception of the academic as social actors. We conclude that the teaching problematization of didactics in nursing presents a potential for humanizing education.
\end{abstract}

KEYWORDS: Higher education; Educational models; Nursing students.

\section{POTENCIALIDADES DE LA PROBLEMATIZACIÓN FREIREANAEN LAENSEÑANZADE "DIDÁCTICA EN ENFERMERÍA"}

RESUMEN: La implicación del modelo pedagógico en la postura de los futuros profesionales es defendida por la literatura. Este estudio tuvo por objetivo investigar la percepción de los académicos de enfermería sobre la utilización de problematización fundamentada en los presupuestos freireanos en una disciplina de didáctica. Consiste en investigación cualitativa, con datos tratados en la perspectiva hermenéutica dialéctica, oriundos de análisis documental de los informes producidos por treinta y cuatro alumnos de una Universidad Federal de la Región Norte del Brasil, en el primer semestre de 2009. Los conocimientos teóricos, a partir del empírico, permitieron la abertura del diálogo, la aproximación de la vida de los usuarios y auto-percepción de los académicos como actores sociales. Concluimos que la problematización de la enseñanza de didáctica en Enfermería presenta potencialidades para una educación humanizadora.

DESCRIPTORES: Educación Superior; Modelos educacionales; Estudiantes de enfermería.

\footnotetext{
${ }^{1}$ Enfermeiro. Doutor em Enfermagem Psiquiátrica. Professor Adjunto do Departamento de Saúde Pública da Universidade Federal de Santa Catarina-UFSC.

²Acadêmica do Curso de Graduação em Enfermagem da Universidade Federal do Amazonas-UFAM.

${ }^{3}$ Enfermeira. Professora Auxiliar da Escola de Enfermagem de Manaus-UFAN.
}

Autor correspondente:

Rodrigo Otávio Moretti-Pires

Universidade Federal de Santa Catarina

Campus Universitário Trindade, 8804-970 - Florianópolis-SC, Brasil

Recebido: 29/09/09

E-mail: rodrigo.moretti@pq.cnpq.br

Aprovado: 30/04/10

Cogitare Enferm. 2010 Abr/Jun; 15(2):308-13 


\section{INTRODUÇÃO}

Ensino é o processo pelo qual o aprender é facilitado por outra pessoa, possibilitando que o educando vivencie situações com potencial de modificações na vida concreta. Este processo é baseado fundamentalmente em três componentes: alguém que ensina, alguém que aprende e algo que o primeiro ensina ao segundo ${ }^{(1)}$. Aprender é reflexo manifesto da experiência do aluno ao ensino dos conhecimentos específicos facilitados pela instrução do professor, e se baseia em determinadas estratégias propostas pela formação que se anseia, contribuindo com a vivência do educando antes de tudo como ser no mundo ${ }^{(1)}$.

Na teoria de Paulo Freire ${ }^{(2)}$, o processo de ensinoaprendizado tem duas configurações: o ensino tradicional/“bancário" e o ensino problematizador. Na educação tradicional o professor ministra aulas expositivas, adotando uma postura conceituada como "depositária” ao entender-se a si mesmo como alguém que transmite o conhecimento narrando fatos e conceitos, e não como facilitadores do aprendizado do educando, mas sim como obrigação( ${ }^{(2)}$. Paralelamente, a problematização supõe a reflexão como ação transformadora inseparável do ato cognoscente e, como ele, inseparável das situações concretas, mesmo que ocorra sobre os conteúdos já elaborados ${ }^{(2-3)}$. O espaço educacional é construído a partir das situações vividas pelos educandos e, com isso, implica em um retorno crítico a essas, produzindo conhecimento e cultura em um mundo e com o mundo ${ }^{(2-3)}$.

O diálogo e a problematização são importantes na formação do profissional crítico e reflexivo, com intuito de responder às necessidades do Sistema Único de Saúde, uma das principais ênfases segundo as Diretrizes Curriculares Nacionais no ensino em Enfermagem $^{(4)}$.

Neste enfoque, os elementos do ensino para a prática em saúde devem ocorrer de forma críticoreflexiva, emancipadora e humanizada ${ }^{(5)}$, em que não apenas os aspectos técnicos, mas também os aspectos humanos e relacionais são imprescindíveis ${ }^{(6)}$.

Estas necessidades pedagógicas da atualidade encontram consonância com diversos pressupostos dos trabalhos de Paulo Freire, tais como: a liberdade como condição necessária na prática educativa; a humanização das relações entre educadores e educandos; a conscientização como processo para leitura do mundo, através do processo educacional; o diálogo, tanto no âmbito do encontro docente-discente, como entre o saber formal e o mundo; o foco na cultura; a reflexão sobre a realidade; a crítica das condições sociais; e, por fim, a problematização dos conteúdos ${ }^{(2)}$. Assim, no ponto extremo entre teoria e filosofia da educação, o pensamento de Freire tem contribuído de forma significante na construção de uma educação reflexiva na Enfermagem, pautada no diálogo entre os educadores e seus educandos ${ }^{(3)}$.

Os enfermeiros, assim como os demais profissionais da área da Saúde, são educadores na prática cotidiana, tanto no contato entre profissional e equipe, assim como desses com os usuários do sistema de saúde. A educação problematizadora é uma das abordagens possíveis para que o profissional seja formado no seio da academia em contraposição à fragmentação do conhecimento próprio do modelo biomédico, que toma o futuro profissional apenas como um reprodutor de técnicas ensinadas pelo modelo pedagógico bancário ${ }^{(3)}$.

Ressalta-se que a perspectiva problematizadora não anula, desmerece ou substitui os aspectos técnicos do ensino profissional em Saúde, mas sim os resignifica, como parte de um processo amplo do "fazer saúde”. Esse processo passa pelo encontro entre o usuário do sistema e o profissional de saúde, que deve ser entendido como um agente de transformações sociais, mais do que apenas como um prestador de cuidados $^{(7)}$.

Tendo em vista o exposto, o presente artigo objetiva investigar a percepção dos acadêmicos sobre a aplicação da metodologia problematizadora, fundamentada nos pressupostos de Paulo Freire, no ensino em Enfermagem ${ }^{(2,5-6,8)}$.

\section{PERCURSO METODOLÓGICO}

O presente estudo consta de pesquisa do tipo análise documental. Utiliza metodologia qualitativa, que permite a compreensão de um fenômeno em suas origens, manifestações e razão de ser, segundo a perspectiva dos sujeitos que o vivenciam, incorporando significado e intenção aos atos, às relações e às estruturas sociais. Essas últimas são tomadas como construções humanas significativas ${ }^{(9)}$, abarcando aspectos da realidade que escapam às simples quantificações e extrapolações ${ }^{(9-10)}$.

Os procedimentos éticos de pesquisa foram obedecidos, em conformidade com a Resolução 196/ 1996 do Conselho Nacional de Saúde, aprovado sob protocolo n. 260/2006. Inexistem conflitos de interesse 
envolvendo o projeto e seus produtos científicos.

O processo ensino-aprendizado investigado referese à Disciplina “Didática Aplicada à Enfermagem”, do curso de graduação em Enfermagem de uma universidade federal da Região Norte do Brasil, desenvolvida no primeiro semestre de 2009. A disciplina teve carga horária de 60 horas, versando sobre as seguintes temáticas semanais: (1) Processo ensino-aprendizado; (2) Metodologia de ensino para grupos específicos (técnicos em Enfermagem, enfermeiros, usuários e equipe de saúde); (3) Técnicas de ensino e didática.

Sobre cada tópico foi entregue, na primeira aula, material teórico aos discentes, que deveriam ler e debater no primeiro momento da aula, em grupos de três estudantes. A seguir, promoveu-se debate entre os presentes e o docente, articulando o conteúdo com a prática de Enfermagem ou a vida dos discentes como cidadãos. A segunda aula foi reservada para exercícios de campo, com coleta de subsídios empíricos, depoimentos de populares e outros elementos da realidade, e registrado o produto em portfólio dos trios de educandos. Na terceira aula houve a apresentação dos produtos pelos grupos. Para encerrar cada tema, após a apresentação dos produtos, promoveu-se amplo debate entre todos os educandos e o educador, terminando com um resgate teórico da temática trabalhada, no sentido de levantar o que a experiência empírica e as discussões possibilitaram na articulação entre a teoria e a prática da Didática em Enfermagem.

Para esta pesquisa, utilizou-se a análise documental, para a qual documento é um registro que se refere à realidade humana, sendo fonte privilegiada de informações sobre a vida e sua história ${ }^{(11)}$. Nesta técnica, o pesquisador vale-se de registros em suas formas originais, sem qualquer tratamento analítico. São as chamadas fontes documentais ${ }^{(11)}$.

A análise foi realizada nas seguintes fontes documentais: (1) Portfólios confeccionados pelos grupos no transcorrer da disciplina, com o registro das discussões sobre cada tópico, apontando a fala de cada componente, sobre o que aprendeu e sua articulação com a futura atividade profissional; (2) Relatório final do grupo, com a avaliação geral do processo e dois tópicos avaliativos específicos: "Comentário geral de como foi a disciplina para mim" e "Críticas e sugestões".

Foram analisados os materiais produzidos por discentes que cumpriram os seguintes critérios de inclusão: ter participado de pelo menos $75 \%$ das aulas da disciplina e declarar anuência formal em participar da pesquisa, através de assinatura do Termo de Consen- timento Livre e Esclarecido. Utilizou-se o produto de 34 discentes, dos 36 que cursaram a disciplina, sendo que dois foram excluídos por não alcançarem o mínimo de frequência estabelecido.

O tratamento dos dados foi realizado por dois pesquisadores, de maneira independente. $\mathrm{Na}$ análise, adotou-se a perspectiva hermenêutica dialética, fundamentando-se nos conceitos gadamerianos sobre a interpretação, mas partindo da postura crítica como fundamental dentro do processo de compreensão, conforme preconizado por Habermas. É uma reflexão que se funda na práxis e busca a compreensão atrelada à análise crítica da realidade ${ }^{(9-10)}$. As etapas do tratamento seguiram o preconizado na literatura, partindo-se da leitura exaustiva do conteúdo, interpretação e busca por categorias (hermenêutica), seguida da reflexão crítico-histórica dos contextos e contradições neles presentes(dialética). Ao término do processo, os dois pesquisadores, junto a um terceiro, finalizaram a análise buscando convergências e divergências.

\section{RESULTADOS}

Os discentes reconhecem a Didática como uma área necessária à atuação do enfermeiro, informação registrada por todos os acadêmicos. Três perspectivas foram preponderantes: didática para o ensino de técnicos, didática para ensino nas equipes de Enfermagem, didática para o ensino na relação pacienteprofissional. De forma marcadamente reincidente, as práticas educativas desenvolvidas na disciplina proporcionaram a interação com diversos públicos no exercício da Enfermagem, desde a capacitação dos profissionais de saúde, sob liderança do enfermeiro, até a interação com usuários durante a ação clínica dos mesmos.

Entre os relatos dos acadêmicos foi apontada a necessidade de que, na ação educativa do enfermeiro com seus pares, sejam contemplados aspectos internos do trabalho em Enfermagem, referindo que esta abordagem é uma ferramenta de aproximação de sujeitos na ação profissional.

Sobremaneira, destacou-se a percepção de que a ação do enfermeiro é muito mais ampla do que as atividades vinculadas às suas responsabilidades clínicas, incluindo também o papel de enfermeiroeducador. Esse, mesmo no nível terciário de atenção à saúde, passa a ter um papel junto à educação para a saúde, no sentido de instruir não apenas sobre hábitos, mas também sobre direitos e deveres, promovendo 
saúde e conscientização.

Outro achado interessante refere-se à Disciplina ministrada como facilitadora para aportes em termos de planejamento e organização das atividades de Enfermagem, na medida em que os membros da equipe são seres humanos, e a Disciplina trabalha a humanização das relações em equipe, principalmente nos tópicos referentes ao processo ensino-aprendizado.

Os acadêmicos apresentaram as características esperadas ao trabalho pertinente à didática, como o facilitar do entendimento do processo ensinoaprendizado, à preparação do enfermeiro para seu papel como docente em cursos técnicos, e como lidar com o educando.

Outra perspectiva apresentada refere-se à utilização da problematização. Em especial, reincidiu que a metodologia utilizada na Disciplina foi uma forma de humanização, no sentido de dar ao educando em Enfermagem possibilidades de se articular com o mundo, seus relacionamentos e o ensino universitário.

O grupo, como um todo, se referiu à problematização como uma nova forma de ensino, considerando que outras disciplinas têm enfoque no modelo tradicional. Os alunis relatam o desejo de que outros docentes também utilizem esta abordagem pedagógica.

O emprego da problematização na Disciplina foi apontado pelos acadêmicos como espaço dialógico e de discussão sobre quanto o ensino tradicional diverge do ensino humanizado. Refletiu-se também acerca da responsabilidade dos acadêmicos sobre o seu próprio ensino, emergindo a temática da "cola" em provas, entendida a partir da teoria freiriana como estratégia de memorização exigida em algumas disciplinas de ensino tradicional nos cursos de Saúde.

\section{DISCUSSÃO}

Inicialmente, é importante ressaltar que a complexidade da ação em Enfermagem, que envolve gerência, assistência e atividades de cunho educativo nos serviços de saúde, exige que o profissional egresso seja comprometido com a realidade concreta da prática nos serviços de saúde. Como tal, o saber referente aos aspectos técnicos da profissão é condição fundamental, com as rotinas de procedimentos e destrezas peculiares ao exercício da Enfermagem.

A complexidade dinâmica das alterações decorrentes da sobrevivência do homem, em suas necessidades biológicas, físicas, emocionais e sociais, permeia, compõe e surge também na prática de Enfermagem. A atuação do enfermeiro frente ao paciente não se dá somente no aspecto biológico, mas também traz potenciais para a transformação, socialização e, principalmente para o aprendizado constante. Entendendo o processo de trabalho como uma ferramenta de transformação humana intencional, há o despertar da valorização no próprio ser que realiza a ação e em quem é realizado ${ }^{(10)}$. Neste sentido, o educador em saúde há que reconhecer a vocação ontológica do ser-sujeito histórico, temporal, criativo e cultural que é o educando, sendo que a educação se constitui como rocesso de transformação e autonomia do educandos( ${ }^{(2)}$.

A racionalidade técnica dos cursos de Saúde e não apenas do curso de Enfermagem, é insuficiente para garantir a formação de um profissional nesta perspectiva, considerando que não propicia a aproximação e reflexão frente a situações do desenvolvimento profissional ${ }^{(12)}$. No transcorrer do processo ensino-aprendizado, voltado à saúde, o profissional deve incorporar e compartilhar ações que levem em conta os ideais de bem comum, atuando de maneiras nas quais o profissional e os clientes possam contemplar-se, atuando como sujeitos e como cidadãos. Desta maneira, o acadêmico e o profissional devem ser estimulados a desenvolver potencialidades como mais um meio para a compreensão dos processos de transformação pessoal e de seu entorno ${ }^{(13)}$.

A confluência no aprendizado dos conteúdos técnicos e do ensino de valores humanos possibilita ganhos para os educandos ao aproximá-los da vida concreta dos usuários. O educador favorece o educando a perceber o momento do cuidado também como atividade de Educação em Saúde. Assim, o profissional não se torna o “dono do cuidado”, aprende a ter uma atitude horizontalizada no ato de cuidar $^{(3)}$.

A imagem tradicional do ensino como processo de transmitir conhecimentos privilegiava a amplitude e a profundidade do conhecimento do docente, interligando -as com a qualidade da aprendizagem dos estudantes. Logo, o acréscimo da visão problematizada ao processo ensino-aprendizado permite ampliar as informações técnicas em Enfermagem, e a natureza de sua competência profissional ${ }^{(12)}$.

Nessa perspectiva, os educandos são os atores principais da aprendizagem e os educadores tornamse mediadores do processo, dando apoio, ajuda e buscando, ao mesmo tempo, desafiar, provocar e incentivar a construção do saber. Por fim, eles orientam o educando a obter autonomia no aprendizado, pois o saber não pode ser considerado algo a ser memorizado, 
incorporado ou transmitido, mas sim produto de construção conjunta ${ }^{(14)}$.

O uso da problematização facilitou o processo de imersão em realidades e culturas diferentes, criando um espaço de esclarecimento e diálogo sobre qual profissional os acadêmicos pretendem ser no futuro, o que é corroborado em outras experiências na literatu$\mathrm{ra}^{(14)}$. O contato com aspectos individuais facilitou dos alunos a descoberta de potencialidades para a prática profissional, desempenhando assim um papel fundamental na formação dos futuros enfermeiros, para que aprendam a lidar tanto com o indivíduo e a família, como com a comunidade ${ }^{(15)}$.

Neste sentido, é válido ponderar sobre o papel das instituições de ensino nas disciplinas críticodialógicas. A priorização daquelas com conteúdo apenas biomédico pode constituir um dos empecilhos para a formação de profissionais que atuem além dos aspectos técnicos. Disciplinas com componentes de humanização, muitas vezes, são isoladas e com pouca importância no rol das matrizes curriculares, quando estes aspectos deveriam ser transversais na formação dos profissionais da área da Saúde ${ }^{(15-16)}$.

Nas situações em que se torna possível ao aluno perceber-se enquanto pessoa e mostrar-se não somente como futuro profissional, sua participação no processo é maximidada e obtém valor. Reforça-se a idéia de que ensinar é dispor naturalmente a aprendizagem, proporcionando existência de condições para que o outro, a partir dele mesmo, aprenda e cresça ${ }^{(12,15)}$.

Como acadêmicos do curso de Enfermagem, os educandos por vezes se encontram confusos, concentrando-se na prática do exercício profissional, na habilidade pessoal e na capacidade humana. Estes aspectos não se referem apenas aos conhecimentos técnicos, mas implicam em processos internos, de sua formação como ser humano. Faz-se necessário proporcionar ao educando conduzir sua "história" para o processo de aprendizado, para que o conteúdo a ser aprendido tenha real significação. Usualmente, esta forma de aprendizagem é valorizada por docentes, os quais identificam a importância do desenvolvimento pessoal do aluno, sobretudo no processo de formação de profissionais que têm a própria interação pessoal como recurso necessário à sua atuação profissional ${ }^{(15)}$.

A problematização permite ao educando apreender a realidade e modificá-la, dando atenção às suas relações com o meio em que vive ${ }^{(2)}$. Nesse contexto, as ações do educador passam por transformações cotidianas e o desenvolvimento do processo ensino- aprendizado potencializa a construção de responsabilidade, pelos próprios passos do educando, com mais autonomia e independência ${ }^{(2)}$.

Os profissionais de Saúde precisam ser capazes de identificar os níveis de suas ações no processo educativo, refletindo sobre a necessidade de se desvincular da prática estritamente assistencial, e colocando-se como educadores, entendendo não serem os donos do saber e sim cooperadores e partícipes deste processo transformador ${ }^{(16)}$.

No entanto, quando o ensino tradicional impõe a dependência ao saber do "outro", ele justifica a postura de que o profissional, ao graduar-se, é um especialista e que este "novo outro" - o usuário do sistema - não tem aporte intelectual suficiente para agir e por isso recorre ao profissional. É a reprodução da imagem semelhante à do educando que se apoia apenas no conhecimento bancário de seu educador.

No enfoque problematizador, o educando é considerado ser no mundo e, como tal, merecedor de saberes tão importantes quanto o saber técnico. Da união destes saberes valida-se uma construção em saúde como possibilidade de autonomia e mudança social, indo à raiz das relações sociais que fundamentam os problemas de saúde da população.

Algumas lacunas emergem após a análise e tratamento dialético dos resultados. A primeira referese aos docentes, importante parte do contexto investigado e que não tiveram voz no presente projeto. A postura dos professores está intimamente implicada no contexto, devendo se pautar na perspectiva de que ensinar é mais que transmitir conhecimentos. Segundo a perspectiva freireana, o ensino cria possibilidades para produção do conhecimento, e neste processo tanto educador como educando são sujeitos e objetos ${ }^{(17)}$.

Outra perspectiva a ser investigada refere-se à formação para as dificuldades enfrentadas pelo profissional. Estudiosas ${ }^{(18)}$ apontam que o enfermeiro desenvolve as competências gerenciais na graduação de maneira parcial, tanto pela limitação da estrutura curricular quanto pela imaturidade do acadêmico, restando serem desenvolvidas ou aperfeiçoadas durante a vida profissional. O ensino deve apontar aos educandos a necessidade de compromisso consigo mesmos sobre o processo ensino-aprendizado, tanto na graduação como na vida profissional ${ }^{(18)}$.

\section{CONSIDERAÇÕES FINAIS}

No transcorrer deste estudo, foi possível perce- 
ber o envolvimento e compromisso dos alunos com o processo ensino-aprendizado. O ensino problematizador pode se constituir em importante estratégia importante para que o acadêmico reflita sobre sua atuação como sujeito com o mundo - histórico e em transformações constantes - e no qual o profissional necessita adaptar-se para atuar.

A abertura para uma prática dialógica permitiu que emergisse a preocupação dos acadêmicos quanto ao seu papel de futuro enfermeiro - como cuidador, assim como educador. O profissional tem papel na educação para a saúde, construindo saberes com os usuários, tanto em termos de direitos como deveres, ampliando assim a conscientização e promoção da saúde.

O modelo adotado na Disciplina "Didática aplicada à Enfermagem” possibilitou ao educando a visão sobre diversificação do ensinar e do aprender, o que não é possível apenas com o ensino tradicional. A contribuição da Disciplina na formação profissional parte de uma visão em que o profissional irá se deparar com diferentes indivíduos, contextos e formas de pensar, devendo oferecer uma assistência que satisfaça as necessidades, tanto técnicas como emocionais, do usuário.

\section{REFERÊNCIAS}

1. Bordenave JD, Pereira AM. Estratégias de ensinoaprendizagem. Petrópolis: Vozes; 1997.

2. Freire P. Pedagogia do oprimido. São Paulo: Paz e Terra; 2000.

3. Miranda KCL, Barroso MGT. A contribuição de Paulo Freire à prática e educação crítica em Enfermagem. Rev Latino-Am Enfermagem. 2004;12(4):631-5.

4. Brasil. Conselho Nacional de Educação Superior. Resolução CNE/CES 3/2001, de 9 de novembro de 2001. Institui diretrizes curriculares nacionais dos cursos de graduação em Enfermagem. Diário Oficial da República Federativa do Brasil, Brasília, 9 nov. 2001. Seção 1.

5. Moretti-Pires RO. Complexidade em saúde da família e formação do futuro profissional de saúde. Interface Comun Saúde Educ. 2009; 28(14).

6. Freire P. Conscientização, teoria e prática da libertação: uma introdução ao pensamento de Paulo Freire. São Paulo: Moraes; 1980.

7. Moretti-Pires RO. O pensamento crítico-social de Paulo Freire sobre humanização e o contexto da formação do enfermeiro, do médico e do odontólogo [tese]. Ribeirão Preto (SP): Universidade de São Paulo; 2008.

8. Freire P. Educação como prática da liberdade. Rio de Janeiro: Paz e Terra; 1999.

9. Minayo, MCS. O desafio do conhecimento: pesquisa qualitativa em saúde. São Paulo: Hubitec; 1999.

10. Berg BL. Qualitative research methods for the social sciences. Long Beach:Pearson; 2004.

11. Ludke M, André MEAD. Pesquisa em educação: abordagens qualitativas. São Paulo: EPU; 2005.

12. Faria JIL, Casagrande LDR. A educação para o século XXI e a formação do professor reflexivo na Enfermagem. Rev Latino-Am Enfermagem. 2004;12(5):821-7.

13. L’Abbate S. Educação e serviços de saúde: avaliando a capacitação dos profissionais. Cad Saúde Pública. 1999;15(Supl 2):15-27.

14. Peres HHC, Meira KC, Leite MMJ. Ensino de didática em enfermagem mediado pelo computador: avaliação discente. Rev Esc Enferm USP. 2007;41(2):271-8.

15. Esperidião E, Munari DB, Stacciarini JMR. Desenvolvendo pessoas: estratégias didáticas facilitadoras para o autoconhecimento na formação do enfermeiro. Rev Latino-Am Enfermagem. 2002;10(4):51622.

16. Oliveira HM, Gonçalves MJF. Educação em saúde: uma experiência transformadora. Rev Bras Enferm. 2004;57(6):761-3.

17. Ribeiro PC. Resenha crítica da obra "Pedagogia da autonomia”. Cogitare Enferm, 2008;13(4):616-7.

18. Rothbarth S; Wolff LDG, Peres AM. O desenvolvimento de competências gerenciais do enfermeiro na perspectiva de docentes de disciplinas de administração aplicada à enfermagem. Texto Contexto Enferm. 2009;18(2):321-9. 